\title{
Amplification and overexpression of Aurora- $A$ in esophageal squamous cell carcinoma
}

\author{
SHANG-BIN YANG ${ }^{1 *}$, XIAO-BO ZHOU ${ }^{1 *}$, HONG-XIA ZHU $^{1}$, LAN-PING QUAN $^{1}$, JIN-FENG BAI $^{1}$, \\ JIE HE $^{2}$, YAN-NING GAO ${ }^{3}$, SHU-JUN CHENG ${ }^{3}$ and NING-ZHI XU ${ }^{1}$ \\ ${ }^{1}$ Laboratory of Cell and Molecular Biology, Departments of ${ }^{2}$ Thoracic Surgical Oncology, \\ ${ }^{3}$ Etiology and Carcinogenesis, Cancer Institute and Cancer Hospital, Chinese Academy \\ of Medical Sciences and Peking Union Medical College, 100021 Beijing, P.R. China
}

Received November 15, 2006; Accepted December 21, 2006

\begin{abstract}
Aurora-A/BTAK/STK15 gene which encodes a centrosome-associated kinase is located on chromosome 20q13.2, a highly amplified region in various human tumors. Recent studies have demonstrated the overexpression and amplification of Aurora-A in many malignant human cancers. The purpose of this study was to investigate the amplification and expression of Aurora- $A$ in esophageal squamous cell carcinoma. Amplification of Aurora-A was determined by fluorescence in situ hybridization in 7 esophageal cancer cell lines and real-time PCR in 29 esophageal cancer samples. We detected Aurora-A expression in 7 esophageal cancer cell lines and 38 esophageal cancers samples by semi-quantitative reverse transcription-PCR and Western blot hybridization. The amplification of Aurora-A was detected in 27 of 29 (93.1\%) esophageal cancer samples and 6 of 7 $(85.7 \%)$ cancer cell lines. Aurora-A was overexpressed in 27 of $38(71.1 \%)$ esophageal cancer samples and all 7 esophageal cancer cell lines. We conclude that Aurora-A is amplified and overexpressed in esophageal squamous cancer.
\end{abstract}

\section{Introduction}

The centrosomes are important for cells to maintain genomic stability through establishment of bipolar spindles during cell division, which could allow equal segregation of replicated chromosome to split into two daughter cells. The centrosomal function is strictly regulated by various proteins. Aurora

Correspondence to: Dr Ning-Zhi Xu, Laboratory of Cell and Molecular Biology, Cancer Institute and Cancer Hospital, Chinese Academy of Medical Sciences and Peking Union Medical College, Panjiayuan, Chaoyang District, P.O. Box 2258, 100021 Beijing, P.R. China

E-mail: xningzhi@public.bta.net.cn

*Contributed equally

Key words: amplification, overexpression, Aurora-A, esophageal squamous cell carcinoma kinase family, a conserved mitotic serine/threonine kinase family, played a vital role in regulating the centrosomal and microtubule function, ensuring accurate chromosome segregation and efficient completion of cytokinesis $(1,2)$. Among the three members of this family, Aurora-A, attracted most attention because Aurora-A gene is mapped to chromosome 20q13.2, a region amplified commonly in epithelial cancers (3-6).

Amplification and/or overexpression of Aurora-A is detected in several types of tumors, including gastric cancer, bladder cancer, gliomas and hepatocellular cancers (7-12). Combining with the studies that overexpression of Aurora-A can transform NIH3T3 and Rat1 cells $(13,14)$ and increase the incidence of breast cancer in transgene mouse (15), most researchers would consider Aurora- $A$ as an oncogene.

ESCC is the fourth most prevalent malignancy in China, but the molecular mechanism for the tumorigenesis of esophageal cancer remains to be elucidated. Gain of chromosome $20 \mathrm{q}$ was often observed in ESCC (16-20). There are no studies investigating DNA status of oncogene Aurora-A located on the 20q in ESCC despite recent reports showing the overexpression of Aurora-A in ESCC $(12,21)$. Therefore, to further reveal the possible role of Aurora-A in esophageal cancer, we detected the DNA copies and expression level of Aurora- $A$ in both esophageal cancer cells lines and primary tumor samples.

\section{Materials and methods}

Cell culture. Seven types of esophageal cancer cell lines KYSE150, 180, 410, 510, 70 (kindly provided by Professor Yutaka Shimada), ESCC109, ESCC9706 (kindly provided by Professor Mingrong Wang) and HLF (human lung fibroblast cell, kindly provided by Dr Youyong Lv, Peking University School of Oncology and Beijing Institute for Cancer Research, Beijing, P.R. China) were cultured in RPMI-1640 medium supplemented by $10 \%$ fetal bovine serum at $5 \% \mathrm{CO}_{2}$.

Clinical tissue sample collection. We obtained 38 esophageal squamous cell carcinoma tissues and corresponding normal tissues from surgically resected esophageal carcinoma at the Cancer Hospital. None of the patients investigated received 
chemotherapy or radiotherapy prior to the operation. All the samples were histopathologically diagnosed as esophageal squamous cell carcinoma.

Fresh samples were dissected manually to remove connective tissues and stored immediately at $-80^{\circ} \mathrm{C}$ until analyzed. The corresponding normal tissues were obtained from the distant edge of dissected esophagus without carcinoma cell invasion by pathological diagnosis. Every tissue sample contained over $80 \%$ of normal or tumor epithelial cells.

Fluorescence in situ hybridization (FISH). Cells were treated with $1 \mu \mathrm{g} / \mathrm{ml}$ colchicines overnight. Then the metaphase cell slides were made according to standard protocol.

Dual-color FISH was undertaken to detect 20q13.2 amplification in esophageal cancer cell lines. We co-hybridized an Aurora-A specific BAC probe (kindly provided by Dr Subrata Sen and Ms. Hongyi Zhou, University of Texas, M.D. Anderson Cancer Center) with a chromosome 20 specific centromere probe. The probes were labeled with biotin or digoxin by nick translation using Nick Translation Kit (Gibco/ BRL, Rockville, MD, USA). Hybridization was performed at $37^{\circ} \mathrm{C}$ for $48 \mathrm{~h}$ in a moist chamber. After hybridization, the slides were washed in $50 \%$ formamide/2X SSC three times for $5 \mathrm{~min}$ each, followed by washes in 2X SSC three times for 5 min each time. Then the slides were blocked by $4 \mathrm{X}$ SSCB (4X SSC with $0.5 \%$ Blocking Regent bought from Roche $0.02 \% \mathrm{NaN}_{3}$ ) at room temperature for $30 \mathrm{~min}$. The slides were incubated with Avidin-FITC in wet chamber at $37^{\circ} \mathrm{C}$ for $60 \mathrm{~min}$ followed by three washings at room temperature for $5 \mathrm{~min}$ in $4 \mathrm{X} \mathrm{SSC}$. Amplification of the signals was performed by biotinylated anti-avidin antibody (Vector Laboratories, Burlington, Canada). At $37^{\circ} \mathrm{C}$ for 60 min in a moist chamber followed by three washings at room temperature with 5 min wash in $4 \mathrm{X}$ SSC. A final incubation with Avidin-FITC and Rhodamine-anti-digoxigenin (Roche, Mannheim, Germany) (working solution: $5 \mu \mathrm{g}$ AvidinFITC $/ \mathrm{ml}$ in $4 \mathrm{X} \mathrm{SSC}, 0.5 \%$ blocking reagent, $0.2 \% \mathrm{NaN}_{3}$ ) was done at $37^{\circ} \mathrm{C}$ for $60 \mathrm{~min}$ in a moist chamber followed by three washings at room temperature for $5 \mathrm{~min}$ in $4 \mathrm{X}$ SSCB. The nuclei were counterstained with DAPI.

The 20q13.2 amplification was recognized by comparison of the numbers of red and green signals in cell nuclei. Approximately 100-200 cells were numbered for each type of cells when summarizing the 20q13.2 amplification rate.

RNA extraction and semi-quantitative RT-PCR. Total-RNA was extracted from paired specimen of primary esophageal cancer and non-cancerous esophageal epithelium with TRIzol Reagent (Invitrogen, Carlsbad, CA, USA) according to the manufacturer's protocol.

Five microgram of total-RNA extracted from paired esophageal carcinoma was used as template respectively to synthesize cDNA in $25 \mu 1$ reaction mixture with $2.5 \mathrm{mM}$ oligo(dT) primers and M-MLV Reverse Transcriptase (Promega, Madison, WI, USA) at $37^{\circ} \mathrm{C}$ for $1 \mathrm{~h}$ followed by $85^{\circ} \mathrm{C}$ for $10 \mathrm{~min}$. PCR was performed in $20 \mu 1$ reaction mixture [1X AmpliTaq buffer, $100 \mathrm{ng}$ template cDNA, $200 \mu \mathrm{M}$ of each dNTPs, $0.5 \mu \mathrm{M}$ of each primers and $2 \mathrm{U}$ AmpliTaq (Roche)] as follows: $95^{\circ} \mathrm{C}$ for $5 \mathrm{~min}$ followed by 24 cycles of $95^{\circ} \mathrm{C}$ for $1 \mathrm{~min}, 56^{\circ} \mathrm{C}$ for $1 \mathrm{~min}, 72^{\circ} \mathrm{C}$ for $1 \mathrm{~min}$, and the final step of extension was for $10 \mathrm{~min}$ at $72^{\circ} \mathrm{C}$. Sequences of the PCR primers for Aurora-A are as follows: upper primer: 5'GCCTCCTGTGAAGACACCAT-3'; lower primer: 5'-ACTT TGTAACAGAGGGAGCC-3' with an expected product of $471 \mathrm{bp}$. B-actin was used as internal control (upper: 5'-GGCG GCACCACCATGTACCCT-3' and downstream: 5'-AGGGG CCGGACTCGTCATACT-3') at 202 bp. Negative control was the amplification omitting the template from the reaction. The reaction products were visualized by electrophoresis of $5 \mu 1$ reaction mixture at $70 \mathrm{~V}$ for $40 \mathrm{~min}$ in $2 \%$ agarose gel containing $0.5 \mu \mathrm{g} / \mathrm{ml}$ ethidium bromide, and quantitated by densitometry using Gel-Pro Analyzer version 3.1 (Media Cybernetics, Silver Spring, MD, USA).

Real-time polymerase chain reaction. To detect the amplification in cancer samples, real-time PCR was performed in the Rotor-Gene RG-3000 Real-Time Thermal Cycler (Corbett Research, Sydney, Australia), which detects the signal from the fluorogenic probe during PCR. As both the precise amount of genomic DNA and its quality are difficult to assess, we also quantified a control gene glyceraldehyde-3phosphate dehydrogenase $(G A P D H)$. All data were normalized to GAPDH.

The ratio defining the level of amplification is termed 'Am', and is determined as follows:

$$
A m=\frac{\mathrm{T}_{\text {the ratio of gene copy number of Aurora-A to GAPDH }}}{\mathrm{N}_{\text {the ratio of gene copy number of Aurora-A to GAPDH }}}
$$

( $\mathrm{T}$, tumor tissues; $\mathrm{N}$, corresponding normal tissues).

The kinetic method requires a standard curve which was constructed with serial 10-fold dilutions of specific PCR products. And in this study, we constructed two standard curves with two different pairs of primers used later for real-time quantitative PCR to quantify Aurora-A and GAPDH gene copy number separately.

PCR amplifications were done with SYBR Premix Ex Taq (Perfect Real-Time) Kit (Takara Biotechnology, Dalian, P.R. China) according to the manufacturer's protocol. The amplification mixes $(25 \mu 1)$ contains SYBR Premix Ex Taq $12.5 \mu 1$, ROX Reference Dye $0.5 \mu 1$, each primer $0.5 \mu 1$ (200 nM) and template $2 \mu 1$ (around $20 \mathrm{ng}$ ). The fragment of Aurora-A was amplified with the primers 5'-CCTTCGAATGTTGGCAGG AT-3' and 5'-TCCAACACTAACAGACCGCA-3'. Internal control GAPDH used the primers 5'-TGAAGGTCGGAGTC AACGGA-3' and 5'-CATGTGGGCCATGAGGTCCA-3'. PCR was performed as follows: $94^{\circ} \mathrm{C}$ for $10 \mathrm{sec}$ followed with 40 cycles of $94^{\circ} \mathrm{C}$ for $5 \mathrm{sec}$ and $60^{\circ} \mathrm{C}$ for $30 \mathrm{sec}$. The software Rotor-Gene 5.0 calculated the parameter $C_{t}$ (threshold cycle) and determined the starting copy number in the samples.

We investigated 29 cancer samples and their corresponding normal tissues. The ratio of Aurora-A copy number to the copy number of $G A P D H$ indicated the gene copy number level of Aurora-A.

Western blot analyses. In order to determine the expression levels of Aurora-A in esophageal cancer cell lines and cancer samples, the frozen tissues after trituration and culture cells 

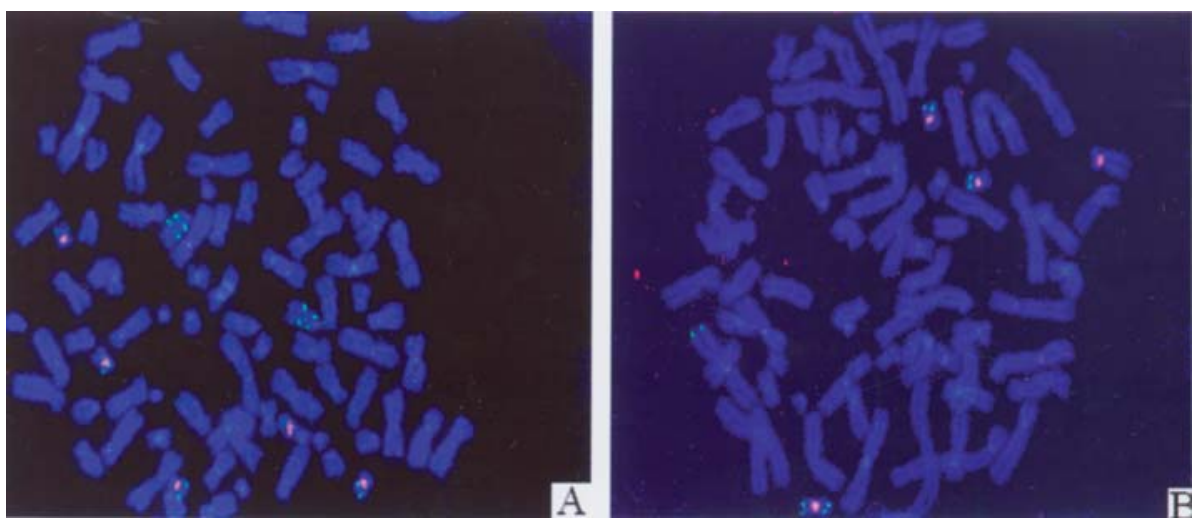

Figure 1. Amplification of Aurora-A in esophageal cancer cell lines. Fluorescence in situ hybridization was used to detect the amplification of Aurora-A in metaphase cells by using Aurora-A gene specific probe (green signal) and centromere probe for chromosome 20 (red signal). There are more green signals than red signals in esophageal cancer cells KYSE410 (A) and KYSE510 (B).

Table I. Amplification of Aurora-A in esophageal cancer cell lines.

\begin{tabular}{|c|c|c|c|c|c|}
\hline \multirow{2}{*}{$\begin{array}{l}\text { Esophageal cancer } \\
\text { cell lines }\end{array}$} & \multirow{2}{*}{ Numbered cell } & \multicolumn{2}{|c|}{ Ratio $^{a}$} & \multirow{2}{*}{$\begin{array}{l}\text { Amplification rate } \\
\qquad(\%)\end{array}$} & \multirow{2}{*}{$\begin{array}{l}\text { High amplification } \\
(\%)\end{array}$} \\
\hline & & $1-1.5$ & $\geq 1.5$ & & \\
\hline KYSE150 & 113 & 6 & 93 & 87.6 & 82.3 \\
\hline KYSE410 & 144 & 18 & 125 & 99.3 & 86.8 \\
\hline KYSE510 & 152 & 121 & 3 & 81.6 & 1.97 \\
\hline KYSE180 & 131 & 24 & 107 & 100 & 81.7 \\
\hline KYSE70 & 172 & 4 & 0 & 2.32 & 0 \\
\hline ESCC109 & 106 & 93 & 2 & 89.6 & 1.89 \\
\hline ESCC9706 & 144 & 82 & 11 & 64.6 & 7.64 \\
\hline
\end{tabular}

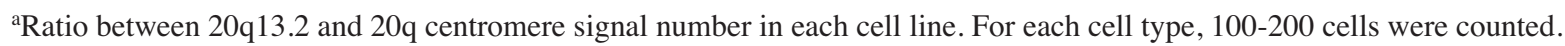

were lysed in RIPA lysis buffer containing $1 \mathrm{X}$ PBS (137 mM $\mathrm{NaCl}, 2.7 \mathrm{mM} \mathrm{KCl}, 10 \mathrm{mM} \mathrm{Na}_{2} \mathrm{HPO}_{4}, 2 \mathrm{mM} \mathrm{KH}_{2} \mathrm{PO}_{4}, \mathrm{pH}$ 7.4), $1 \%$ NP40, $0.5 \%$ sodium deoxycholate, $0.1 \%$ SDS, $1 \mathrm{mM}$ PMSF, $1 \mu \mathrm{g} / \mathrm{ml}$ aprotinin and $5 \mu \mathrm{g} / \mathrm{ml}$ leupeptin. Lysates were centrifuged at $12,000 \mathrm{~g}$ for $15 \mathrm{~min}$ at $4^{\circ} \mathrm{C}$. The protein concentration was determined using BCA Protein Assay Kit (Pierce, Rockford, IL, USA). Equal amounts of total proteins were then separated on $12 \%$ acrylamide gels using standard sodium dodecyl sulfate-polyacrylamide gel electrophoresis (SDS-PAGE) techniques. After transfer to nitrocellulose membranes (Optitran, Schleicher\&Schuell, Keene N.H., USA), the proteins were detected with anti-Aurora-A antibody (N20; 1:1000; Santa Cruz, CA, USA), followed by anti-goat IgG-horseradish peroxide-conjugated secondary antibody (Zhongshan Co., Beijing, P.R. China) and chemiluminescence luminol detection kit (Santa Cruz). The same membrane was reprobed with anti- $\beta$-actin (AC-15; 1:5000; Sigma, St Louis, MO, USA) as a control for equivalent protein loading.

\section{Results}

Amplification of Aurora-A in esophageal cancer cell lines. Using an Aurora-A gene specific probe and centromere probe for chromosome 20, we detected the Aurora-A gene copy increments in esophageal cancer cell lines by FISH (Fig. 1). Each numbering included 100-200 metaphase cells, and total amplification rate in each cell type was calculated. Then the cells were assorted into amplification and high amplification of Aurora-A based on the ratio of 20q13.2 to 20q signals. Six out of seven esophageal cancer cell lines have amplified Aurora-A, three of which showed high amplification of Aurora-A (Table I).

We also found many isochromosomes of 20q13.2, which is a common feature of aneuploidy and gene amplification in cancer.

Amplification of Aurora-A in esophageal cancers. Quantitative real-time PCR was done to detect the amplification of Aurora- $A$ in esophageal cancer tissues. Twenty-nine paired cancer samples and distant normal esophageal epithelium were investigated to evaluate the gene copy level of Aurora-A by using GAPDH as internal control.

GAPDH standard curve was constructed (Fig. 2) and then quantitative real-time PCR was done to detect the GAPDH gene copy number (Fig. 3). The same experiment was done to detect the Aurora-A gene copy number. The starting copy numbers were determined by the software Rotor-Gene 5.0, 


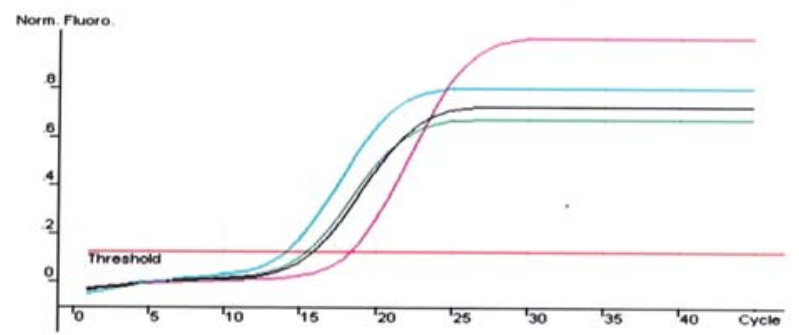

B

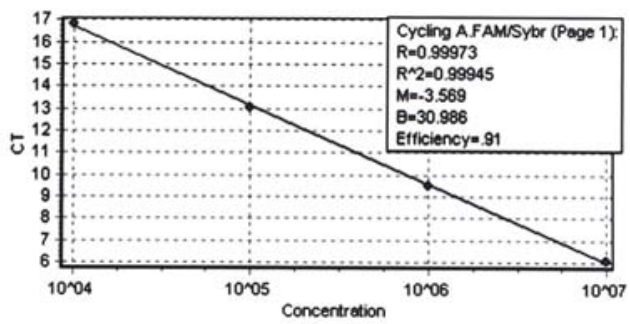

Figure 2. GAPDH standard curve by real-time PCR. Four real-time polymerase chain reactions were done with serial 10 -fold dilutions of specific PCR products of GAPDH as template (A). The parameter $\mathrm{C}_{\mathrm{t}}$ (threshold cycle) was determined by software Rotor-Gene 5.0, and the standard curve was constructed based on the $\mathrm{C}_{\mathrm{t}}$ and the template concentration of the four samples (B).

and all the data were normalized to $G A P D H$. As showed in Table II, 27 of $29(93.1 \%)$ cancer samples possessed higher Aurora-A gene copy level than their corresponding normal tissues. Therefore Aurora-A is amplified in ESCC.

Overexpression of Aurora-A in esophageal cancers and cancer cell lines. We tested the expression level of Aurora-A gene in 7 esophageal cancer cell lines by semi-quantitative reverse transcription PCR analysis and Western blot assay. We used HLF cell (human lung fibroblast cell) as a normal control. All esophageal cancer cell lines showed overexpression of Aurora-A compared with HLF cells at mRNA level, KYSE70, 410 and ESCC9706 also have higher expression of Aurora-A from protein level detection (Fig. 4).

We also detected mRNA expression level of Aurora-A in esophageal cancer samples (Fig. 5). Comparison of band densitometry between Aurora-A and $B$-actin by software showed $71.1 \%$ (27/38) esophageal cancer samples had more
Table II. Amplification of Aurora-A in esophageal cancers.

\begin{tabular}{llr}
\hline & \multicolumn{2}{c}{ Amplification level (Am) } \\
\cline { 2 - 3 } & $<1(\%)$ & $>1(\%)$ \\
\hline No. of patients & $2(6.9)$ & $27(93.1)$ \\
\hline
\end{tabular}

KYSE70 $150 \quad 180 \quad 410 \quad 510 \quad$ ESCC109 $9706 \quad$ HLF

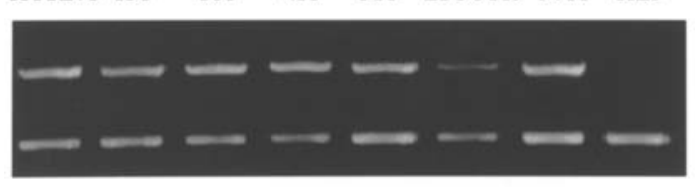

Aurora-A

$\beta$-actin

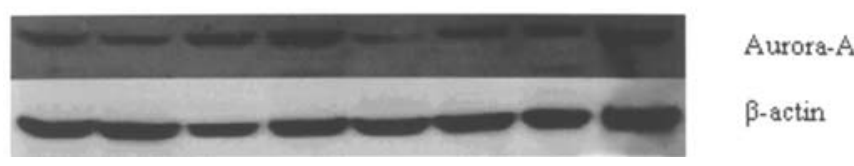

Figure 4. Overexpression of Aurora-A in esophageal cancer cell lines. Reverse transcription PCR showed increased Aurora-A mRNA level in 6 out of 7 esophageal squamous cell carcinomas (upper panel). HLF cell (human lung fibroblast cell) is the normal control. Protein level of Aurora-A was assayed by immunoblotting in 7 esophageal cancer cell lines by using HLF cells as normal control (lower panel). Six of seven esophageal cancer cell lines showed overexpression of Aurora-A at protein level. The membranes were reprobed with $B$-actin as a loading control.

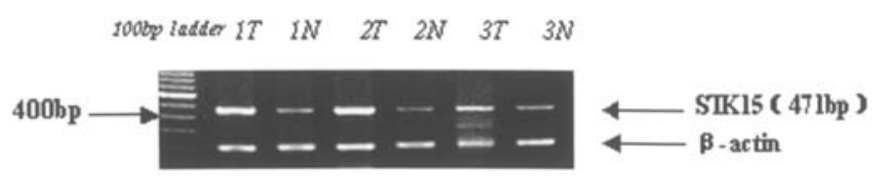

Figure 5. Expression of Aurora-A in esophageal cancers. Semi-quantitative RT-PCR of ESCC tissues. Aurora-A mRNA expression in esophageal cancers (T) was higher than the corresponding normal tissues $(\mathrm{N})$. Aurora-A fragment (471 bp) was amplified with specific primers and $\beta$-actin was used as internal control.

than 1.5-fold increase of Aurora-A mRNA level in contrast to paired normal adjacent tissues (Table III).

In addition to RT-PCR analysis, ten cancer specimens were collected and assayed for Aurora-A expression by Western immunoblot analysis. Six Cancer samples showed increased

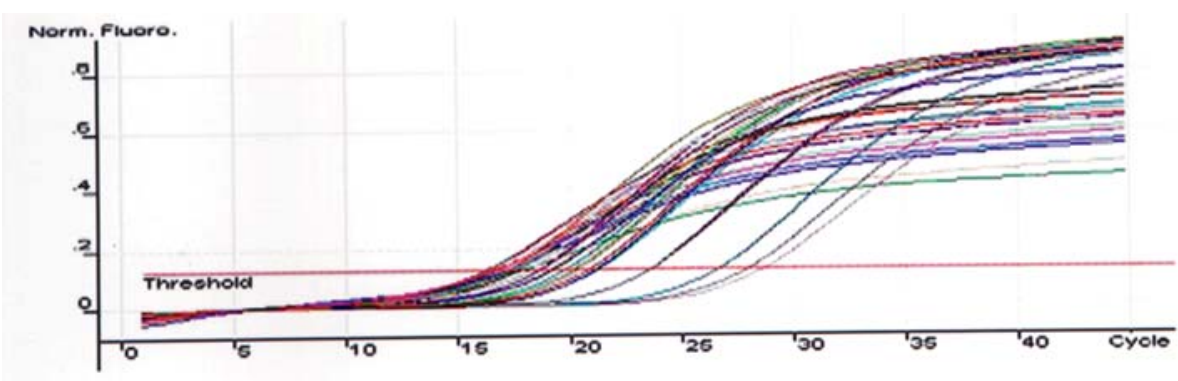

Figure 3. GAPDH gene copy number was detected by quantitative real-time PCR. Real-time PCR was performed to evaluate the GAPDH gene levels in esophageal cancers, the different color curves represent different samples. 
Table III. Overexpression of Aurora-A in esophageal cancers.

\begin{tabular}{lccc}
\hline & $\begin{array}{c}\text { Elevated STK15 } \\
\text { expression } \\
(\%)\end{array}$ & $\begin{array}{c}\text { No change of } \\
\text { STK15 expression } \\
(\%)\end{array}$ & $\begin{array}{c}\text { Total } \\
(\%)\end{array}$ \\
\hline $\begin{array}{l}\text { No. of } \\
\text { patients }\end{array}$ & $27(71.1)$ & $11(28.9)$ & $38(100)$ \\
\hline
\end{tabular}

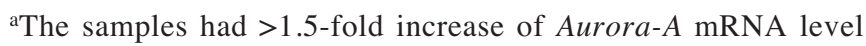
compared to that of the normal control.

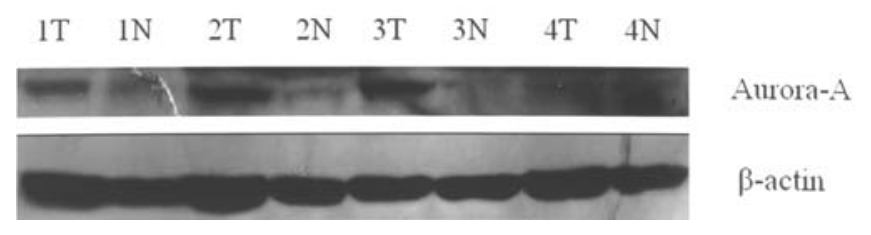

Figure 6. Aurora-A was overexpressed at the protein level in esophageal cancers. Analysis of Aurora-A protein expression in human ESCC tissues by Western blot assay. Cell lysates were prepared from clinical esophageal cancers and normal adjacent tissues ( $\mathrm{T}$, tumor; $\mathrm{N}$, corresponding normal tissues). The same membrane was reprobed with anti- $\beta$-actin as a loading control.

protein level of Aurora-A in human esophageal squamous cell carcinoma (Fig. 6).

\section{Discussion}

Esophageal cancer is the seventh leading cause of cancer death worldwide. In China, more than $90 \%$ of esophageal cancer is the squamous cell carcinoma type, and the area of the high incidence of ESCC is in the north. According to epidemiological studies, there are multiple etiological factors, such as nutritional deficiency, toxic stimuli, hot food ingestion and genetic background, contributing to the development of esophageal cancer. Because esophageal cancer usually is not diagnosed until the late stage and the disease has spread, prognosis of esophageal cancer is very poor. Fewer than $20 \%$ of people survive more than 5 years (22), therefore novel approaches to the early diagnosis and treatment of this malignant tumor are urgently needed, and understanding the molecular mechanism of human esophageal squamous cell carcinoma is the key to any such approach.

In our present study, we demonstrated amplification and overexpression of Aurora-A/STK15 in esophageal cancer cell lines and esophageal cancer tissues.

Previous comparative genomic hybridization studies in esophageal cancer cell lines and tissues revealed that $20 \mathrm{q}$ amplification is common in esophageal cancers, but the genes involved in $20 \mathrm{q}$ gain are poorly identified. Given that the frequent $20 \mathrm{q}$ amplification in breast cancer and bladder cancer is often accompanied by the overexpression of Aurora-A $(23,24)$, a mitosis regulating gene located on 20q13.2, we proposed Aurora-A as the possible target gene on amplified $20 \mathrm{q}$ in the esophageal cancer. In our present study, we identified frequent amplification of Aurora-A locus at 20q13.2 in seven esophageal cancer cell lines by dual-color FISH assay and in cancer samples by real-time PCR assay. Semi-quantitative RT-PCR was used to detect the expression of Aurora-A in esophageal cancer tissues. We found $27 / 38$ $(71.1 \%)$ esophageal cancers with elevated expression of Aurora- $A$ when compared with corresponding normal tissues, which is consistent with other recent reports that Aurora- $A$ is overexpressed in human ESCC $(12,21)$. In addition, there are recent reports showing that the Aurora-A polymorphism is associated with ESCC risk $(25,26)$. Although the relationship between the overexpression and polymorphism of Aurora-A needs to be further revealed, the polymorphism in Aurora-A gene was demonstrated to be associated with an increased risk in ESCC, as well as in breast cancer (25-27). Therefore, the studies, including ours, strongly suggested Aurora-A involvement in the Chinese esophageal cancer development and progression.

Aurora-A/BTAK/STK15 gene, located in 20q13, frequently amplified chromosome region in many tumors including ESCC shown in our present study, belongs to a serine/threonine kinase family (Aurora kinase family) implicated in equal segregation of chromosomes between daughter cells. Aurora$\mathrm{A}$ is important to centrosome duplication, maturation and accurate separation as well as to bipolar spindle assembly and stability. Its crucial role in the normal cell division suggested that change of Aurora-A expression might contribute to the aberrant cell growth in cancer. In fact, ectopic overexpression of Aurora-A in mammalian cells has been demonstrated to cause centrosome amplification, leading to aneuploidy. More importantly, overexpression of Aurora-A can lead to genetic instability and cause mammary tumor development in transgene mouse, which indicated that overexpressed Aurora-A could function as a potential oncogene causing carcinogenesis in many solid tumors.

Taken together, our present studies on the overexpression and amplification of Aurora-A in ESCC have provided indicative clues to revealing the mechanism of esophageal carcinogenesis and to find regimens to improve survival of esophageal cancer patients. Although the cause which triggers Aurora-A amplification and the mechanism involved during carcinogenesis in human solid tumors still need to be deeply investigated, the efficient therapy targeting Aurora-A in other malignant tumors (28-31) could also bring hope to esophageal cancer patients if the vital role that Aurora-A plays in esophageal cancer could be addressed further.

\section{Acknowledgements}

We thank Professor Subrata Sen for 20q BAC clones; Professor Yutaka Shimada for KYSE cell lines and Professor Mingrong Wang for EC9706 cells. This study was supported by National Natural Science Foundation (39925020, 30271451) and National Basic Research Program (G1998051204, 2004CB518701), P.R. China.

\section{References}

1. Marumoto T, Hirota T, Morisaki T, et al: Roles of aurora-A kinase in mitotic entry and G2 checkpoint in mammalian cells. Genes Cells 7: 1173-1182, 2002. 
2. Dutertre S, Descamps S and Prigent C: On the role of aurora-A in centrosome function. Oncogene 21: 6175-6183, 2002.

3. Schlegel J, Stumm G, Scherthan H, Bocker T, Zirngibl H, Ruschoff $\mathrm{J}$ and Hofstadter F: Comparative genomic in situ hybridization of colon carcinomas with replication error. Cancer Res 55: 6002-6005, 1995.

4. Reznikoff CA, Belair CD, Yeager TR, Savelieva E, Blelloch RH, Puthenveettil JA and Cuthill S: A molecular genetic model of human bladder cancer pathogenesis. Semin Oncol 23: 571-584, 1996.

5. Forozan F, Mahlamaki EH, Monni O, et al: Comparative genomic hybridization analysis of 38 breast cancer cell lines: a basis for interpreting complementary DNA microarray data. Cancer Res 60: 4519-4525, 2000.

6. Jazaeri AA, Lu K, Schmandt R, et al: Molecular determinants of tumor differentiation in papillary serous ovarian carcinoma. Mol Carcinog 36: 53-59, 2003.

7. Klein A, Reichardt W, Jung V, Zang KD, Meese E and Urbschat S: Overexpression and amplification of STK15 in human gliomas. Int J Oncol 25: 1789-1794, 2004.

8. Jeng YM, Peng SY, Lin CY and Hsu HC: Overexpression and amplification of Aurora-A in hepatocellular carcinoma. Clin Cancer Res 10: 2065-2071, 2004.

9. Li D, Zhu J, Firozi PF, et al: Overexpression of oncogenic STK15/BTAK/Aurora A kinase in human pancreatic cancer. Clin Cancer Res 9: 991-997, 2003.

10. Sen S, Zhou H, Zhang RD, et al: Amplification/overexpression of a mitotic kinase gene in human bladder cancer. J Natl Cancer Inst 94: 1320-1329, 2002.

11. Kamada K, Yamada Y, Hirao T, et al: Amplification/overexpression of Aurora-A in human gastric carcinoma: potential role in differentiated type gastric carcinogenesis. Oncol Rep 12: 593-599, 2004.

12. Tanaka E, Hashimoto Y, Ito T, et al: The clinical significance of Aurora-A/STK15/BTAK expression in human esophageal squamous cell carcinoma. Clin Cancer Res 11: 1827-1834, 2005.

13. Zhou H, Kuang J, Zhong L, et al: Tumour amplified kinase STK15/BTAK induces centrosome amplification, aneuploidy and transformation. Nat Genet 20: 189-193, 1998.

14. Ewart-Toland A, Briassouli P, De Koning JP, et al: Identification of Stk6/STK15 as a candidate low-penetrance tumorsusceptibility gene in mouse and human. Nat Genet 34: 403-412, 2003.

15. Wang X, Zhou YX, Qiao W, Tominaga Y, Ouchi M, Ouchi T and Deng CX: Overexpression of Aurora kinase A in mouse mammary epithelium induces genetic instability preceding mammary tumor formation. Oncogene (In press).

16. Wei F, Ni J, Wu SS, et al: Cytogenetic studies of esophageal squamous cell carcinomas in the northern Chinese population by comparative genomic hybridization. Cancer Genet Cytogenet 138: 38-43, 2002 .

17. Fujita Y, Sakakura C, Shimomura K, et al: Chromosome arm $20 \mathrm{q}$ gains and other genomic alterations in esophageal squamous cell carcinoma, as analyzed by comparative genomic hybridization and fluorescence in situ hybridization. Hepatogastroenterology 50: 1857-1863, 2003.
18. Moskaluk CA, Hu J and Perlman EJ: Comparative genomic hybridization of esophageal and gastroesophageal adenocarcinomas shows consensus areas of DNA gain and loss. Genes Chromosomes Cancer 22: 305-311, 1998.

19. Yen CC, Chen YJ, Chen JT, et al: Comparative genomic hybridization of esophageal squamous cell carcinoma: correlations between chromosomal aberrations and disease progression/ prognosis. Cancer 92: 2769-2777, 2001.

20. Yen CC, Chen YJ, Lu KH, et al: Genotypic analysis of esophageal squamous cell carcinoma by molecular cytogenetics and real-time quantitative polymerase chain reaction. Int J Oncol 23: 871-881, 2003.

21. Tong T, Zhong Y, Kong J, et al: Overexpression of Aurora-A contributes to malignant development of human esophageal squamous cell carcinoma. Clin Cancer Res 10: 7304-7310, 2004.

22. Parkin DM, Bray F, Ferlay J and Pisani P: Global cancer statistics, 2002. CA Cancer J Clin 55: 74-108, 2005.

23. Klein A, Jung V, Zang KD, et al: Detailed chromosomal characterization of the breast cancer cell line MCF7 with special focus on the expression of the serine-threonine kinase 15. Oncol Rep 14: 23-31, 2005.

24. Fraizer GC, Diaz MF, Lee IL, Grossman HB and Sen S: Aurora-A/STK15/BTAK enhances chromosomal instability in bladder cancer cells. Int J Oncol 25: 1631-1639, 2004.

25. Miao X, Sun T, Wang Y, Zhang X, Tan W and Lin D: Functional STK15 Phe31Ile polymorphism is associated with the occurrence and advanced disease status of esophageal squamous cell carcinoma. Cancer Res 64: 2680-2683, 2004.

26. Kimura MT, Mori T, Conroy J, Nowak NJ, Satomi S, Tamai K and Nagase $\mathrm{H}$ : Two functional coding single nucleotide polymorphisms in STK15 (Aurora-A) coordinately increase esophageal cancer risk. Cancer Res 65: 3548-3554, 2005.

27. Sun T, Miao X, Wang J, Tan W, Zhou Y, Yu C and Lin D: Functional Phe31Ile polymorphism in Aurora A and risk of breast carcinoma. Carcinogenesis 25: 2225-2230, 2004.

28. Mahadevan D, Bearss DJ and Vankayalapati H: Structure-based design of novel anti-cancer agents targeting aurora kinases. Curr Med Chem Anti-Cancer Agents 3: 25-34, 2003.

29. Vankayalapati H, Bearss DJ, Saldanha JW, Munoz RM, Rojanala S, von Hoff DD and Mahadevan D: Targeting aurora2 kinase in oncogenesis: a structural bioinformatics approach to target validation and rational drug design. Mol Cancer Ther 2: 283-294, 2003.

30. Hata T, Furukawa T, Sunamura M, et al: RNA interference targeting aurora kinase a suppresses tumor growth and enhances the taxane chemosensitivity inhuman pancreatic cancer cells. Cancer Res 65: 2899-2905, 2005.

31. Harrington EA, Bebbington D, Moore J, et al: VX-680, a potent and selective small-molecule inhibitor of the Aurora kinases, suppresses tumor growth in vivo. Nat Med 10: 262-267, 2004. 